\title{
Ocular Intracameral Pharmacokinetics for a Cocktail of Timolol, Betaxolol, and Atenolol in Rabbits
}

Anam Fayyaz, ${ }^{*} \dagger, \ddagger \odot$ Veli-Pekka Ranta, ${ }^{\ddagger}$ Elisa Toropainen, ${ }^{\ddagger}$ Kati-Sisko Vellonen, ${ }^{\ddagger}$ Giuseppe D’Amico Ricci, ${ }^{\S} \|$ Mika Reinisalo, ${ }^{\ddagger}, \perp$ Emma M. Heikkinen, ${ }^{\ddagger}{ }^{\dagger}$ Iain Gardner, ${ }^{\dagger}$ Arto Urtti, ${ }^{\ddagger}$ Masoud Jamei, ${ }^{\dagger}{ }^{\dagger}$ and Eva M. del Amo ${ }^{\#}$

${ }^{\dagger}$ Certara UK, Simcyp Division, Level 2-Acero, 1 Concourse Way, Sheffield S1 2BJ, U.K.

${ }^{\ddagger}$ University of Eastern Finland, School of Pharmacy, Biopharmaceutics, Yliopistonranta 1, 70210 Kuopio, Finland

${ }^{\S}$ University of Sassari, Department of Biomedical Sciences, Sassari, Italy

"Asl Città di Torino, Ospedale Oftalmico di Torino, U.O.C Oculistica 2, Ospedale San Giovanni Bosco di Torino, Torino, Italy

${ }^{\perp}$ Institute of Clinical Medicine, Department of Ophthalmology, Faculty of Health Sciences, University of Eastern Finland, 70210 Kuopio, Finland

"University of Manchester, Division of Pharmacy \& Optometry, Oxford Road, Manchester M13 9PL, U.K.

Supporting Information

ABSTRACT: The mechanisms of drug clearance from the aqueous humor are poorly defined. In this study, a cocktail approach was used to simultaneously determine the pharmacokinetics of three $\beta$-blocker agents after intracameral (ic) injection into the rabbit eyes. Aqueous humor samples were collected and analyzed using LC-MS/MS to determine drug concentrations. Pharmacokinetic parameters were obtained using a compartmental fitting approach, and the estimated clearance, volume of distribution, and half-life values were the following: atenolol $(6.44$ $\mu \mathrm{L} / \mathrm{min}, 687 \mu \mathrm{L}$, and $73.87 \mathrm{~min})$, timolol $(19.30 \mu \mathrm{L} / \mathrm{min}, 937 \mu \mathrm{L}$, and $33.64 \mathrm{~min})$, and betaxolol $(32.20 \mu \mathrm{L} / \mathrm{min}, 1421 \mu \mathrm{L}$, and $30.58 \mathrm{~min}$ ). Increased compound lipophilicity (atenolol < timolol

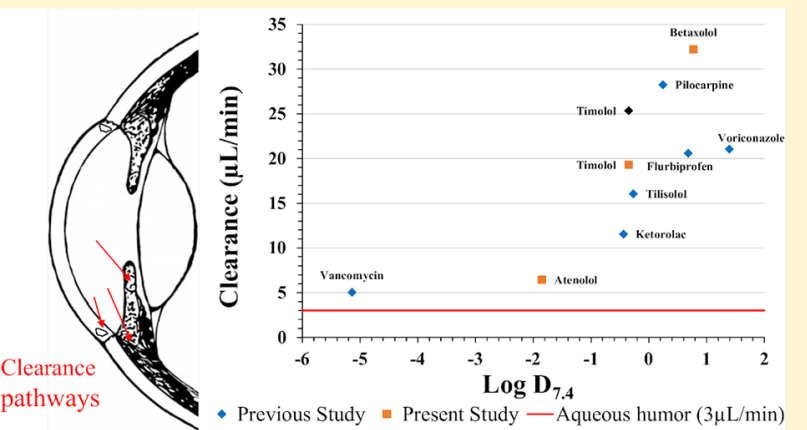
$<$ betaxolol) resulted in higher clearance and volume of distributions in the aqueous humor. Clearance of timolol and betaxolol is about 10 times higher than the aqueous humor outflow, demonstrating the importance of other elimination routes (e.g., uptake to iris and ciliary body and subsequent elimination via blood flow).

KEYWORDS: intracameral injection, clearance, volume of distribution, timolol, atenolol, betaxolol, ocular pharmacokinetics

\section{INTRODUCTION}

$\beta$-Adrenergic antagonists (Figure 1) are used widely for the treatment of glaucoma since they lower the intraocular pressure by reducing the production of aqueous humor $(\mathrm{pH}$ $7.5-7.6^{1,2}$ ) in the ciliary body which can ultimately decrease the outflow of aqueous humor in long-term therapy. ${ }^{3-5}$ Atenolol and betaxolol selectively inhibit adrenoceptor $\beta_{1}$,
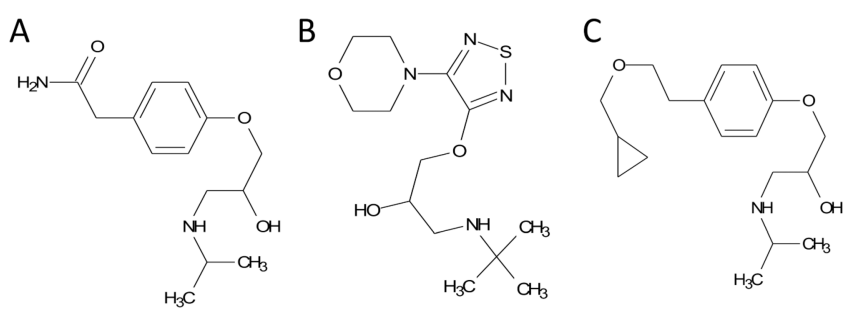

Figure 1. Chemical structure of three $\beta$-blockers: (A) atenolol, (B) timolol, (C) betaxolol. whereas timolol nonselectively antagonizes both $\beta_{1}$ and $\beta_{2}$ receptors. $^{6-8}$

During eye drop treatment, it is important to achieve and maintain adequate drug concentrations in the aqueous humor. ${ }^{9,10}$ From the aqueous humor the small molecular weight drugs permeate with relative ease to the iris and ciliary body, and drug concentrations in these tissues typically closely follow the levels in aqueous humor. ${ }^{11,12}$ Therefore, drug concentrations in the aqueous humor are widely used to monitor ocular drug absorption and to determine the ocular bioavailability.

Drug clearance from the aqueous humor must be known to accurately determine ocular bioavailability following administration of eye drops. Unfortunately, these values have been

Received: September 30, 2019

Revised: November 20, 2019

Accepted: December 3, 2019

Published: December 3, 2019 
only rarely determined, mainly because such experiments require intracameral injections and in preclinical species require a large number of rabbits. Thus, aqueous humor clearance of drugs is a poorly understood and missing piece in ocular pharmacokinetics, and lack of intracameral kinetic information makes it challenging to build reliable mathematical models for topical eye medications. Accurate in silico models for predicting ocular pharmacokinetics would have the potential to replace and/or refine experiments for new topical agents in the future.

Drug clearance from the aqueous humor can take place via aqueous humor outflow through trabecular meshwork ${ }^{13}$ and uveoscleral pathway ${ }^{14}$ or permeation to iris and ciliary body and subsequent elimination by the blood flow in these tissues $^{15-18}$ (Figure 2). Trabecular meshwork outflow is

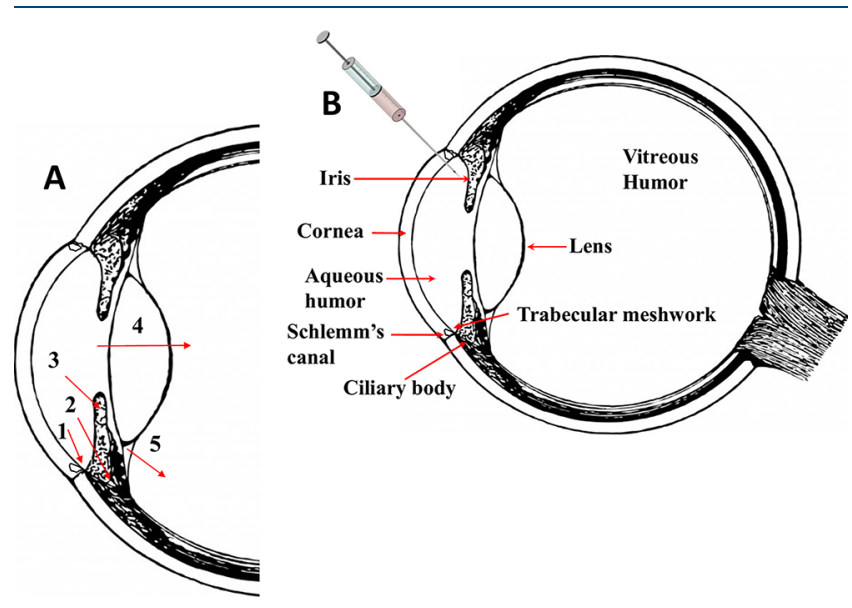

Figure 2. Ocular drug elimination routes after intracameral injection. (A) Elimination of drugs after intracameral injection. (1) Clearance through trabecular meshwork outflow. (2) Clearance through uveoscleral outflow. (3) Elimination to the vasculature of iris and ciliary body. (4) Distribution to lens. (5) Distribution to vitreous humor. (B) Intracameral administration into the aqueous humor. (https://www.publicdomainpictures.net/en/view-image.php?image $=$ 130389\& picture $=$ medical-eye)

approximately $3 \mu \mathrm{L} / \mathrm{min}^{19,20}$ in rabbits, and drug clearance via this pathway is independent of drug's physiochemical properties. ${ }^{11,21-24}$ The importance of other pathways depends on the ability of drug to cross the tissues and endothelial vessels. The iridial and muscle ciliary vessels (other ciliary vessels are leaky) present tight junctions, corresponding to the endothelial component of the blood-aqueous barrier. ${ }^{25,26}$ Drugs that can easily permeate through these barriers present much faster clearance values. ${ }^{18,27,28,23,26}$ Obviously, drugs may also distribute to the neighboring tissues, i.e., iris-ciliary body, vitreous humor and lens, and these may affect the apparent drug volume of distribution. ${ }^{11,29}$ (Figure 2).

In this study, ocular pharmacokinetics of three $\beta$-blocker agents were determined using a cocktail dosing strategy. The three compounds were given in a single injection solution dosed intracamerally to anesthetized albino rabbits. The cocktail approach reduces the number of animals in the experiments to one-third. To the best of our knowledge, this is the first time a cocktail approach is used for intracameral injection in rabbits.

\section{MATERIALS AND METHODS}

Preparation of Drug Solution. solutions of $3 \mathrm{mM}$ atenolol (USP reference standard, Sigma), $3 \mathrm{mM}$ betaxolol hydrochloride (USP reference standard, Sigma), and $3 \mathrm{mM}$ timolol maleate (USP reference standard, Sigma) were prepared in phosphate buffered saline (PBS) at $\mathrm{pH}$ 7.4. The solutions were diluted to obtain drug mix solution that contained $1 \mathrm{mM}$ of each $\beta$-blocker (atenolol, betaxolol, and timolol). The $\mathrm{pH}$ of the $\beta$-blocker mix solution was 7.4 , and osmolality $267 \mathrm{mOsm} / \mathrm{kg}$ was evaluated just prior to use.

Animal Experiments. New Zealand albino rabbits (males, weight 2.7-3.1 kg; Envigo Laboratories UK) were used in the study. The animals were handled in accordance with the statement of the Animals in Research Committee of the ARVO (Association for Research in Vision and Ophthalmology, Rockville, MD, USA), and the experiments were approved by the National Animal Experiment Board in Finland.

Before the experiment, the animals' eyes were examined to confirm the ocular health. The animals were sedated with medetomidine (Domitor vet $1 \mathrm{mg} / \mathrm{mL}$, Orion Pharma, Espoo, Finland; dose $0.5 \mathrm{mg} / \mathrm{kg}$ ) injection subcutaneously and anesthetized with ketamine (Ketalar/Ketaminol $50 \mathrm{mg} / \mathrm{mL}$, Pfizer Oy Animal Health, Espoo, Finland; dose $25 \mathrm{mg} / \mathrm{kg}$ ). The pupils were dilated (tropicamide; Oftan Tropicamide 5 $\mathrm{mg} / \mathrm{mL}$, Santen Pharmaceutical Co., Ltd., Tampere, Finland), and the surfaces of the eyes were locally anesthetized (Oftan Obucain $4 \mathrm{mg} / \mathrm{mL}$, Santen Pharmaceutical Co., Ltd., Tampere, Finland).

Intracameral injections were performed under direct ophthalmoscopic control through an operating microscope. A beveled, multiplanar self-sealing clear corneal incision ${ }^{30}$ was performed in the opposite side of the nictitating membrane. An angled $1.8 \mathrm{~mm}$ slit knife was flattened against the eye, and the tip was used to enter the cornea just anterior to the vascular arcade. The blade was advanced tangentially to the corneal surface until the shoulders of the blade were fully buried in the stroma. Then, the point of the blade was redirected posteriorly so that the point and the rest of the blade enter the anterior chamber parallel to the iris. The drug was delivered into the anterior chamber through the clear conceal incision by a $34 \mathrm{G}$ needle. Both eyes of each rabbit were injected with the injection volume of $5 \mu \mathrm{L}$ /eye.

The animals were sacrificed at designated times $(10,20,30$, $60,120,180$, and $240 \mathrm{~min}$ ) by injecting a lethal dose of pentobarbitone (Mebunat vet $60 \mathrm{mg} / \mathrm{mL}$, Orion Pharma, Espoo, Finland; dose $120 \mathrm{mg} / \mathrm{kg}$ ) into the marginal ear vein. Immediately after death, the aqueous humor was withdrawn from the eyes. The samples were stored at $-80{ }^{\circ} \mathrm{C}$ until analysis.

Aqueous Humor Samples. Analytical standards (0.1$5000 \mathrm{nM}$ ) were prepared from $1 \mathrm{mM} \beta$-blocker mix in PBS and diluted with solution containing $20 \%$ porcine aqueous humor and $80 \%$ of PBS.

Atenolol-d7 (Toronto Research Chemicals, Canada), betaxolol-d5 (Toronto Research Chemicals, Canada), and timolol-d5 maleate (Toronto Research Chemicals, Canada) were used as internal standards (ISTD). Stock solutions (1 $\mathrm{mg} / \mathrm{mL}$ ) were first prepared in DMSO and then diluted to the final ISTD solution containing $100 \mathrm{ng} / \mathrm{mL}$ atenolol-d7, $10 \mathrm{ng} /$ $\mathrm{mL}$ betaxolol-d5, $10 \mathrm{ng} / \mathrm{mL}$ timolol-d5 maleate, and $1 \%$ formic acid in acetonitrile. 

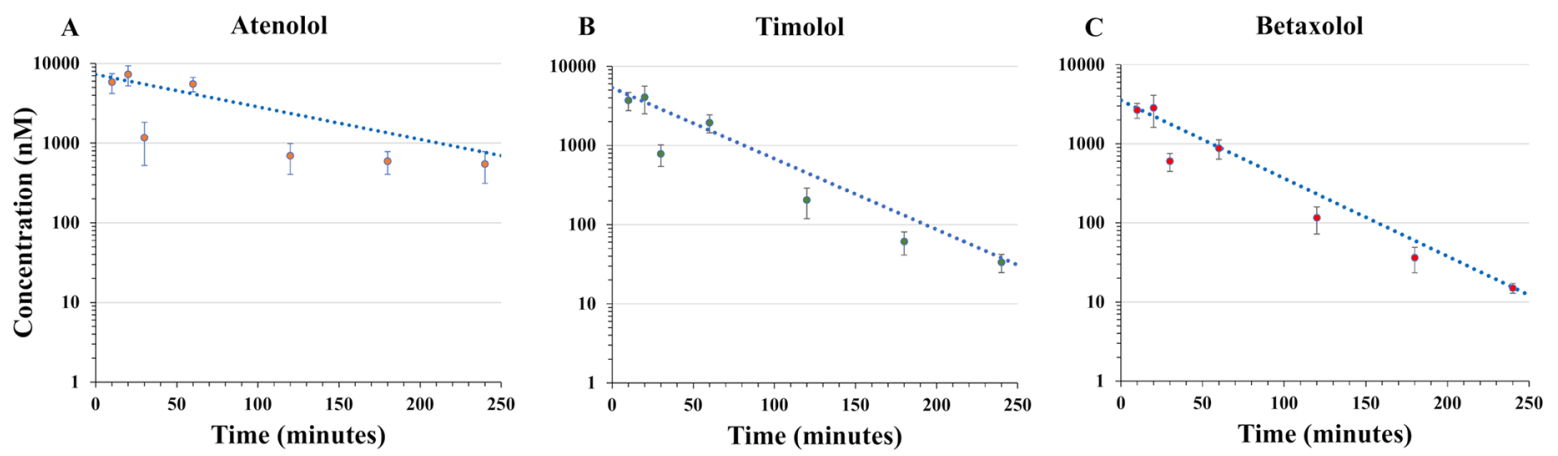

Figure 3. Concentrations of atenolol (A), timolol (B), and betaxolol (C) after intracameral injections. Each point represents the mean concentration $(n=2-4) \pm$ standard error of the mean (concentration-time values are presented in Supporting Information Table S3). Onecompartmental curve fit with1/Yhat ${ }^{2}$ weighting is shown for each compound (blue lines).

Equal volumes $(75 \mu \mathrm{L})$ of standard solutions and ISTD solution were mixed by vortexing for $10 \mathrm{~s}$. Then the samples were incubated at room temperature for $15 \mathrm{~min}$ to precipitate proteins, centrifuged ( $\left.5 \mathrm{~min},+4{ }^{\circ} \mathrm{C}, 13000 \mathrm{rpm}\right)$, and supernatant was collected for LC-MS analysis. Quality control samples $(2.5,25,250$, and $1500 \mathrm{nM})$ in triplicates were prepared in the same manner.

Aqueous humor samples were first diluted 1:5 with PBS (containing $14 \mu \mathrm{L}$ of $\mathrm{AH}+56 \mu \mathrm{L}$ of PBS), and then ISTD solution was added. Thereafter, processing of the samples was as described for the standards. Samples from time points 180 and $240 \mathrm{~min}$ were also analyzed without dilution with PBS, and these were chosen for pharmacokinetic analysis since few timolol and betaxolol concentrations in the diluted samples were below LOQ.

The standards, samples, and quality control samples were analyzed using LC-MS/MS (Agilent 1290 liquid chromatograph and Agilent 6495 triple quadruple mass spectrometer, Agilent Technologies Inc., USA). For HPLC separation Agilent Poroshell 120 SB-C18 column $(2.7 \mu \mathrm{m}, 2.1 \mathrm{~mm} \times$ $50 \mathrm{~mm}$ ) maintained at $50{ }^{\circ} \mathrm{C}$ and eluent flow rate of $0.5 \mathrm{~mL} /$ min were used. Eluent A was $0.1 \%$ formic acid (eluent additive for LC-MS, Fluka) in Milli-Q-water, and eluent B was methanol (Ultra Chromasolv for LC-MS, Honeywell, Riedelde Haën). The elution gradient was as follows: $2 \%$ eluent B for $2 \mathrm{~min}$, then linear rise to $100 \% \mathrm{~B}$ in $5 \mathrm{~min}$, then linear decrease to $2 \%$ eluent $\mathrm{B}$ in $0.1 \mathrm{~min}$ and kept at $2 \%$ up to $9 \mathrm{~min}$. Injection volume was $1 \mu \mathrm{L}$. Two product ions were monitored for each compound employing MRM mode (multiple reaction monitoring mode). The following MS conditions were used: capillary voltage $3.5 \mathrm{kV}$, nebulizer $25 \mathrm{psi}$, gas temperature 200 ${ }^{\circ} \mathrm{C}$, gas flow $16 \mathrm{~L} / \mathrm{min}$, sheath gas heater $350{ }^{\circ} \mathrm{C}$, sheath gas flow $11 \mathrm{~L} / \mathrm{min}$, fragmentor voltage $380 \mathrm{~V}$, dwell time $200 \mathrm{~ms}$, and cell accelerator voltage $5 \mathrm{~V}$. The data were analyzed with Agilent MassHunter Quantitative Analysis software (Supporting Information Table S1).

The calibration curve was prepared in duplicate and calculated as a mean of two injections using 8-10 concentration levels. Standard curves had $85-115 \%$ mean accuracies compared to nominal concentration. Correlation coefficient of curves were $>0.99$. QC samples were $85-115 \%$ of the nominal concentrations. All measured sample concentrations were $>10 \mathrm{nM}$ (Supporting Information Table S2).

Pharmacokinetic Analysis. Compartmental naive pooled data analyses of aqueous humor concentration-time profile (Supporting Information Table S3) after intracameral injection of $\beta$-blockers in aqueous humor were performed using Phoenix WinNonlin (build 8.0, Certara L.P.). Values of clearance $\left(\mathrm{CL}_{\mathrm{IC}}\right)$, volume of distribution $\left(V_{\mathrm{dIC}}\right)$, and half-life $\left(t_{1 / 2 \mathrm{IC}}\right)$ were calculated. One-compartment and two-compartment models were used to fit the data. Different weighting schemes like uniform, 1/concentration predicted (1/Yhat), and 1/ (concentration predicted $)^{2}\left(1 /\right.$ Yhat $\left.^{2}\right)$ were used for curve fitting. Residual plots, CV\% (coefficient of variation: an estimate of reliability of the estimated parameter), SD were compared between the three weighting schemes. Objective function values and AIC (Akaike information criterion: a model discrimination indicator) were used to compare compartment models with the same weighting. ACD/Percepta (version 2254, Advanced Chemistry Development, Inc. Toronto, Canada) was utilized to calculate the molecular descriptors, i.e., $\log D_{7.4}, \log P$, number of hydrogen bond donor (HBD) groups, polar surface area (PSA), and molecular weight (MW), for the three drugs.

\section{RESULTS}

From the in vivo study, most of the aqueous humor samples could be used except for one eye that received accidentally the injection in the corneal endothelium $(20 \mathrm{~min})$ and the other two from the same animal with abnormal eyes (leading to problems in the injection) and markedly different $\beta$-blocker concentrations compared with other animals (times 20 and 60 $\min$ ). A one-compartment model was used to fit the three $\beta$ blockers (two-compartment fitting was also conducted but it was unsuccessful). The $1 /$ Yhat $^{2}$ weighting scheme was finally used because it obtained low $\mathrm{SD}, \mathrm{CV} \%$ values compared the other weighting schemes (for more detailed information see Supporting Information Figures S1-S3). Figure 3 shows the concentration data of all samples of atenolol, timolol, and betaxolol in the aqueous humor after intracameral administration and one-compartmental fitting. Elimination of atenolol was slower than that of timolol and betaxolol.

Table 1 compiles the physicochemical and pharmacokinetic parameters of the three $\beta$-blockers after the intracameral injections. Atenolol with the lowest $\log D_{7.4}$ value $(-1.85)$ showed the lowest clearance value of $6.44 \mu \mathrm{L} / \mathrm{min}$ and the longest half-life of $73.87 \mathrm{~min}$. Timolol $\left(\log D_{7.4}=-0.35\right)$ had faster intracameral clearance $(19.30 \mu \mathrm{L} / \mathrm{min})$ than atenolol but smaller than the value of betaxolol $(32.20 \mu \mathrm{L} / \mathrm{min})$. The results show higher clearance and volume of distribution values and shorter half-life with increasing lipophilicity of the compound. 
Table 1. Estimated Pharmacokinetic Parameters of the Drugs in Aqueous Humor after Intracameral Injections in the Rabbit Eyes $^{a}$

\begin{tabular}{lccccccccc}
\multicolumn{1}{c}{ drug } & $\mathrm{MW}$ & $\log D_{7.4}$ & $\log P$ & $\mathrm{PSA}$ & $\mathrm{HBD}$ & $V_{\mathrm{dIC}} \pm \mathrm{SE}(\mu \mathrm{L})$ & $\mathrm{CL}_{\mathrm{IC}} \pm \mathrm{SE}(\mu \mathrm{L} / \mathrm{min})$ & $t_{1 / 2 \mathrm{IC}} \pm \mathrm{SE}(\mathrm{min})$ & $\mathrm{AUC} \pm \mathrm{SE}(\mathrm{min} \cdot \mathrm{nmol} / \mu \mathrm{L})$ \\
atenolol & 266.34 & -1.85 & 0.24 & 84.5 & 4 & $687 \pm 140$ & $6.44 \pm 0.83$ & $73.87 \pm 12.16$ & $0.781 \pm 0.100$ \\
timolol & 316.42 & -0.35 & 1.53 & 107.9 & 2 & $937 \pm 172$ & $19.30 \pm 2.66$ & $33.64 \pm 2.29$ & $0.266 \pm 0.037$ \\
betaxolol & 307.43 & 0.77 & 2.94 & 50.7 & 2 & $1421 \pm 236$ & $32.20 \pm 4.10$ & $30.58 \pm 1.71$ & $0.159 \pm 0.020$
\end{tabular}

${ }^{a} \log D_{7.4}$ : octanol-water partition (ionized and un-ionized molecules). $\log P$ : octanol-water partition (un-ionized molecules). PSA: polar surface area. HBD: hydrogen bond donor. $V_{\mathrm{d}, \mathrm{IC}}$ : volume of distribution after intracameral injection. $\mathrm{CL}_{\mathrm{IC}}$ : clearance after intracameral injection. $t_{1 / 2, \mathrm{IC}}$ : halflife after intracameral injection. AUC: area under the curve. SE: standard error.

\section{DISCUSSION}

A cocktail approach was developed for the first time for ocular pharmacokinetic rabbit studies. The published rabbit concentrations in rabbit aqueous humor after clinical drug doses in eye drops ${ }^{31-35}$ support that the observed drug concentrations of timolol and betaxolol in aqueous humor were in the clinically relevant range. Atenolol is not clinically approved in ophthalmology. Often the main concern in cocktail studies is the potential pharmacokinetic and pharmacodynamic interaction between the given drugs. Drug-drug interaction can be a concern within cocktail studies. Metabolism and protein binding are not affecting elimination from aqueous humor (no metabolites detected; the protein content in aqueous humor is minimal $\left.{ }^{36}\right)$. The three $\beta$-blockers are P-glycoprotein transporter substrates which are present in ciliary body but their quantification and cellular location are unknown. Overall we do not expect a pharmacokinetic interaction. Given our experimental setting, dose and duration of the study, we do not expect pharmacodynamics interactions either. The study provided the intracameral clearance of three drugs and their apparent volumes of distribution. A trend was seen between the pharmacokinetic parameters and lipophilicity of the drugs.

Intracameral pharmacokinetics have only been sparsely studied (see Supporting Information Table S4) even though it is an important parameter for the determination of topical ocular drug administration. Our study differs from the previous literature studies in the following ways: (1) Cocktail approach was applied for the first time to evaluate the ocular pharmacokinetics of administered drugs in vivo. (2) Ocular pharmacokinetic parameters $\mathrm{CL}_{\mathrm{IC}}, V_{\mathrm{dIC}}$, and $t_{1 / 2}$ IC were evaluated for the first time for atenolol and betaxolol. (3) Timolol kinetics after intracameral injection was followed for 6 h, previously only 2 h. $^{27}$ (4) An indication of relationship was acknowledged between drug lipophilicity and intracameral clearance. Up to 5-fold range difference in clearance was seen between the three $\beta$-blockers.

Previously ocular pharmacokinetic studies have been performed using a single drug administration at a time; however this approach requires a large number of animals. We injected atenolol, timolol, and betaxolol simultaneously into the anterior chamber. This approach reduces the experimental variability, and the number of rabbits could be reduced to onethird. This is in support of $3 \mathrm{R}$ (reduce, refine, replace) principles in animal experiments. However, performing intracameral injection itself is challenging as the angle of injection, site of injection, and aqueous humor leaking cannot always be the same. Although the injection method was standardized using a well-established cataract surgery technique, aqueous humor leaking could not be completely avoided in every injection. The concentration values do show a drop at $30 \mathrm{~min}$ for all three drugs, but there was no experimental justification for excluding these concentrations. Therefore, the data were retained in the pharmacokinetics analysis. This caused some of the variability in our data (Figure 3), but the variability due to injection technique is the same for all drugs in each experiment, unlike in the experiments with a single drug administration. It also facilitates the ease with which comparisons among the compounds can be made.

Atenolol, betaxolol, and timolol are $\beta$-blockers with $\log D_{7.4}$ values of $-1.85,-0.35$, and 0.77 , respectively. The results showed a clear trend in the $\mathrm{CL}_{\mathrm{IC}}$ of the three drugs related to their $\log D_{7.4}$ values. The higher $\log D_{7.4}$ values are associated with the higher clearance values (Figure 4 ). The $3 \mu \mathrm{L} / \mathrm{min}$ flow line in Figure 4 shows the normal aqueous humor turnover rate in rabbits. Clearance faster than $3 \mu \mathrm{L} / \mathrm{min}$ indicates that drug is cleared after permeating into the iris and ciliary body and vessels by the iris and ciliary body blood flows in addition to the aqueous humor outflow mechanisms. ${ }^{11,22,28}$ Lipophilic drugs can more easily permeate into the endothelium of the blood-aqueous barrier than hydrophilic ones. ${ }^{25}$ Atenolol showed clearance of $6.44 \mu \mathrm{L} / \mathrm{min}$ that is 4.8 times less than that of betaxolol. This suggests that a large fraction (47\%) of atenolol is cleared through the aqueous humor outflow ( $3 \mu \mathrm{L} / \mathrm{min}$ vs $6.44 \mu \mathrm{L} / \mathrm{min}$ ), while only $16 \%$ and $9 \%$ of timolol and betaxolol respectively are eliminated by aqueous humor outflow ( $3 \mu \mathrm{L} / \mathrm{min}$ vs $19.30 \mu \mathrm{L} / \mathrm{min}$ and 32.20 $\mu \mathrm{L} / \mathrm{min})$.

Moreover, $V_{\mathrm{dIC}}$ values of atenolol, timolol, and betaxolol (687 $\mu \mathrm{L}, 937 \mu \mathrm{L}, 1421 \mu \mathrm{L})$ suggest that these compounds distribute into the neighboring tissues, i.e., iris-ciliary body, cornea, lens, and vitreous humor, since these values are much greater than the anatomical volume of the aqueous humor (approximately $300 \mu \mathrm{L}$ ).

Timolol has an intermediate lipophilicity; its $\mathrm{CL}_{\mathrm{IC}}$ was 19.30 $\mu \mathrm{L} / \mathrm{min}$ and half-life $33.64 \mathrm{~min}$. These results are similar to the ones obtained by Yamamura and co-workers of $25.33 \mu \mathrm{L} / \mathrm{min}$ clearance, $57.60 \mathrm{~min}$ half-life, and $860 \mu \mathrm{L}$ steady state volume of distribution for intracameral timolol. ${ }^{27}$ We used sampling for longer time ( $6 \mathrm{~h}$ versus $2 \mathrm{~h}$ in Yamamura et al.'s work ${ }^{27}$ ) to fully capture the kinetic profile of timolol. Therefore, the $V_{\mathrm{dIC}}$ and $\mathrm{CL}_{\mathrm{IC}}$ values in our study may provide more reliable estimates for timolol kinetics in the anterior chamber. This is in line with the literature showing that timolol distributes from the aqueous humor to surrounding tissues (cornea, iris-ciliary body, lens). ${ }^{37-40}$

The impact of $\log D_{7.4}$ on clearance and volume of distribution is illustrated in (Figure 4). The plot includes the compounds investigated in the present study and the ones from intracameral pharmacokinetic studies available in the

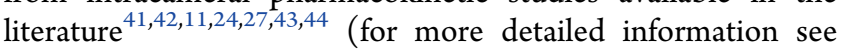
Supporting Information Table S4). Figure 4 shows that very hydrophilic drugs such as vancomycin and atenolol are eliminated predominantly via aqueous humor outflow (CL values slightly faster than $3 \mu \mathrm{L} / \mathrm{min}$ ), whereas at higher 

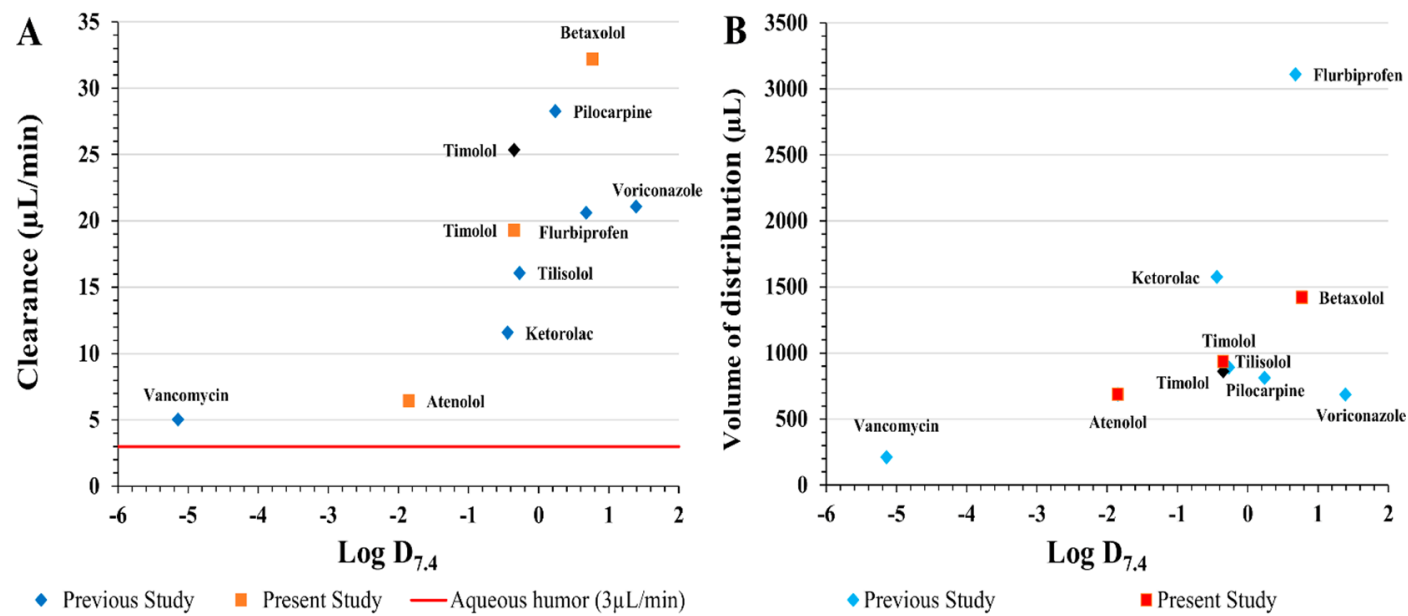

Figure 4. The $\log D_{7.4}$ vs pharmacokinetic parameters of IC administered drugs. Both panels show nine compounds, i.e., betaxolol, atenolol, timolol (from the present study presented by orange squares) and compounds reported in the literature such timolol ${ }^{27}$ (black diamond symbol) and vancomycin, ${ }^{42}$ pilocarpine, ${ }^{11,24}$ voriconazole, ${ }^{43}$ flurbiprofen, ${ }^{41}$ ketorolac, ${ }^{44}$ tilisolol ${ }^{27}$ (blue diamonds). Panel A shows log $D_{7.4}$ vs clearance of drugs after IC administration. The red line in the graph represents the aqueous humor drug clearance value of $3 \mu \mathrm{L} / \mathrm{min}$ through trabecular meshwork. Panel B shows $\log D_{7.4}$ vs volume of distribution of drugs. More detailed information on the IC pharmacokinetic parameters are obtained in the Supporting Information Table S4.

lipophilicity values, the clearance increases several-fold since these drugs are able to potentially permeate more effectively into the iridial and ciliary body endothelial barrier, reaching the blood circulation with blood flows of $62 \mu \mathrm{L} / \mathrm{min}$ in iris and 82 $\mu \mathrm{L} /$ min ciliary body. ${ }^{15,19}$ It seems the clearance is permeability-limited since values are below the iris and ciliary body blood flows.

Moreover, the clearance shows a better correlation with $\log D_{7.4}$ than the volume of distribution (Figure 4B). The clearance and volume of distribution increase are not fully in line with the $\log D_{7.4}$ increase because other factors, such as hydrogen bond donor groups, melanin binding (pigmented rabbits $)^{12,29,45,26}$ and partitioning to the lens, may also contribute to clearance and volume of distribution. ${ }^{29}$ Correlation to other molecular descriptors was also investigated, proving to be poor (see Supporting Information Figure S4).

In addition to ocular bioavailability after topical drug delivery, clearance and volume of distribution also affect drug concentrations in the anterior chamber. It is important to realize that increasing drug lipophilicity leads to higher corneal permeability and ocular bioavailability after eye drop administration. Nevertheless, lipophilicity also increases the clearance and volume of distribution in the anterior chamber. The 5-fold range in clearance and about 1.5 -fold range in volume of distribution are very significant. Therefore, it is important to take intracameral pharmacokinetics into account when designing drugs for ocular administration. This study will help the model building to estimate aqueous humor drug concentrations after topical, subconjunctival, and intravitreal administrations.

\section{CONCLUSION}

Intracameral injection of a mix of three $\beta$ blocking drugs was successfully performed showing that the cocktail approach is feasible in ocular pharmacokinetic studies. Pharmacokinetic parameters of atenolol, timolol, and betaxolol demonstrated a strong dependence of intracameral clearance on the drug lipophilicity (about 5-fold range). The contribution of aqueous humor outflow in ocular elimination ranges from $\approx 50 \%$ (atenolol) to $\approx 10 \%$ (betaxolol) suggesting that most of the drug dose is eliminated by the blood flow of iris and ciliary body. The data can be utilized in building pharmacokinetic models for evaluation and prediction of drug kinetics after ocular administration. The cocktail approach can speed up ocular pharmacokinetic studies and reduce the use of animals.

\section{ASSOCIATED CONTENT}

\section{S Supporting Information}

The Supporting Information is available free of charge at https://pubs.acs.org/doi/10.1021/acs.molpharmaceut.9b01024.

Ion exchange monitored with LC-MS; calibration curves of $\beta$-blockers for aqueous humor samples; compound list for previous intracameral studies and their pharmacokinetic parameters; pharmacokinetic analysis with one-compartment model for atenolol, timolol, and betaxolol; correlation plots between molecular descriptors versus primary pharmacokinetic parameters (PDF)

\section{AUTHOR INFORMATION}

\section{Corresponding Author}

*Phone: +44 (0) 114460 0155. E-mail: anam.fayyaz@certara. com and anamf@student.uef.fi.

ORCID 우

Anam Fayyaz: 0000-0001-9207-8259

Emma M. Heikkinen: 0000-0001-5923-7289

Masoud Jamei: 0000-0002-3443-0194

\section{ACKNOWLEDGMENTS}

The work is supported by OCUTHER from European Union's Horizon 2020 research and Innovation Programme under the Marie Skłodowska-Curie Grant Agreement No. 722717 and EAKR EU regional grant. Eva M. del Amo was supported by European Union's Horizon 2020 Research and Innovation Programme under the Marie Sklodowska-Curie (Grant No. 799880). Emma M. Heikkinen was supported by Doctoral 
Programme in Drug Research (University of Eastern Finland), Academy of Finland (Grant No. 233114), and Päivikki and Sakari Sohlberg Foundation. Arto Urtti was also supported by Russian Mega Grant. Anam Fayyaz, Masoud Jamei, and Iain Gardner are employees of Certara UK Limited, Simcyp Division. Lea Pirskanen is acknowledged for excellent technical support. We thank Annika Valtari (M.Sc.), Jooseppi Puranen (M.Sc.), Dr. Marika Ruponen, and Prof. Seppo Auriola for contributing to the work.

\section{REFERENCES}

(1) Sakanoue, M. Aqueous humor $\mathrm{pH}$ measurement in vivo of the use of a closed system technique with glass capillary electrode. Keio J. Med. 1961, 10 (1), 15-23.

(2) Veselovský, J.; Olah, Z.; Veselá, A.; Gressnerova, S. The pH reaction in aqueous humor to antiglaucoma agents of various concentrations and $\mathrm{pH}$ levels. Cesk. Slov. Oftalmol. 2001, 57 (5), 291-297.

(3) Hong, S.-J.; Wu, K.-Y.; Chen, I.-J. Ocular hypotensive and vasodilative effects of two $\beta$-adrenergic blockers with intrinsic sympathomimetic activity. Curr. Eye Res. 1998, 17 (7), 700-707.

(4) Nathanson, J. A. Stereospecificity of beta adrenergic antagonists: R-enantiomers show increased selectivity for beta- 2 receptors in ciliary process. J. Pharmacol. Exp. Ther. 1988, 245 (1), 94-101.

(5) Kiland, J.; Gabelt, B.; Kaufman, P. Studies on the mechanism of action of timolol and on the effects of suppression and redirection of aqueous flow on outflow facility. Exp. Eye Res. 2004, 78 (3), 639-651.

(6) Hall, J.; Kaumann, A.; Brown, M. Selective beta 1-adrenoceptor blockade enhances positive inotropic responses to endogenous catecholamines mediated through beta 2 -adrenoceptors in human atrial myocardium. Circ. Res. 1990, 66 (6), 1610-1623.

(7) Smith, C.; Teitler, M. Beta-blocker selectivity at cloned human beta1-and beta2-adrenergic receptors. Cardiovasc. Drugs Ther. 1999, 13 (2), 123-126.

(8) Potter, J.; Bannan, L.; Beevers, D. The effect of a non-selective lipophilic beta-blocker on the blood pressure and noradrenaline, vasopressin, cortisol and renin release during alcohol withdrawal. Clin. Exp. Hypertens., Part A 1984, 6 (6), 1147-1160.

(9) Bucci, F. A., Jr.; Nguimfack, I. T.; Fluet, A. T. Pharmacokinetics and aqueous humor penetration of levofloxacin $1.5 \%$ and moxifloxacin $0.5 \%$ in patients undergoing cataract surgery. Clin. Ophthalmol. 2016, 10, 783 .

(10) Ding, W.; Ni, W.; Chen, H.; Yuan, J.; Huang, X.; Zhang, Z.; Wang, Y.; Yu, Y.; Yao, K. Comparison of drug concentrations in human aqueous humor after the administration of $0.3 \%$ gatifloxacin ophthalmic gel, $0.3 \%$ gatifloxacin and $0.5 \%$ levofloxacin ophthalmic solutions. Int. J. Med. Sci. 2015, 12 (6), 517.

(11) Conrad, J. M.; Robinson, J. R. Aqueous chamber drug distribution volume measurement in rabbits.inson, J. R. Aqueous chamber drug distribution volume measurement in rabbits. J. Pharm. Sci. 1977, 66 (2), 219-224.

(12) Lee, V. H.; Robinson, J. R. Disposition of pilocarpine in the pigmented rabbit eye. Int. J. Pharm. 1982, 11 (2), 155-165.

(13) Maurice, D. M. Structures and fluids involved in the penetration of topically applied drugs. International ophthalmology clinics 1980, 20 (3), 7-20.

(14) Nilsson, S. F. The uveoscleral outflow routes. Eye 1997, 11 (2), 149.

(15) Nilsson, S. F.; Alm, A., Determination of ocular blood flows with the microsphere method. In Ocular Blood Flow; Springer, 2012; pp 25-47.

(16) Bill, A.; Törnquist, P.; Alm, A. Permeability of the intraocular blood vessels. Trans. Ophthalmol. Soc. U.K. 1980, 100 (3), 332-336.

(17) Sherman, S. H.; Green, K.; Laties, A. M. The fate of anterior chamber fluorescein in the monkey eye 1 . the anterior chamber outflow pathways. Exp. Eye Res. 1978, 27 (2), 159-173.

(18) Chastain, J. E. General considerations in ocular drug delivery. In Ophthalmic Drug Delivery Systems; CRC Press, 2003; pp 80-129.
(19) del Amo, E. M.; Vellonen, K.-S.; Kidron, H.; Urtti, A. Intravitreal clearance and volume of distribution of compounds in rabbits: In silico prediction and pharmacokinetic simulations for drug development. Eur. J. Pharm. Biopharm. 2015, 95, 215-226.

(20) Kinsey, V. E.; Bárány, E. The rate of flow of aqueous humor: II. Derivation of rate of flow and its physiologic significance. Am. J. Ophthalmol. 1949, 32 (6), 189-202.

(21) Järvinen, K.; Järvinen, T.; Urtti, A. Ocular absorption following topical delivery. Adv. Drug Delivery Rev. 1995, 16 (1), 3-19.

(22) Hornof, M.; Toropainen, E.; Urtti, A. Cell culture models of the ocular barriers. Eur. J. Pharm. Biopharm. 2005, 60 (2), 207-225.

(23) Schoenwald, R. D. Ocular pharmacokinetics and pharmacodynamics. In Ophthalmic Drug Delivery Systems; CRC Press, 2003; pp 156-201.

(24) Miller, S. C.; Gokhale, R. D.; Patton, T. F.; Himmelstein, K. J. Pilocarpine ocular distribution volume. J. Pharm. Sci. 1980, 69 (5), 615-616.

(25) Del Amo, E. M.; Rimpela, A. K.; Heikkinen, E.; Kari, O. K.; Ramsay, E.; Lajunen, T.; Schmitt, M.; Pelkonen, L.; Bhattacharya, M.; Richardson, D.; Subrizi, A.; Turunen, T.; Reinisalo, M.; Itkonen, J.; Toropainen, E.; Casteleijn, M.; Kidron, H.; Antopolsky, M.; Vellonen, K. S.; Ruponen, M.; Urtti, A. Pharmacokinetic aspects of retinal drug delivery. Prog. Retinal Eye Res. 2017, 57, 134-185.

(26) Maurice, D. M.; Mishima, S. Ocular Pharmacokinetics. In Pharmacology of the Eye; Sears, M. L., Ed.; Springer: Berlin, 1984; pp 19-116.

(27) Yamamura, K.; Sasaki, H.; Nakashima, M.; Ichikawa, M.; Mukai, T.; Nishida, K.; Nakamura, J. Characterization of ocular pharmacokinetics of beta-blockers using a diffusion model after instillation. Pharm. Res. 1999, 16 (10), 1596-1601.

(28) Urtti, A; Salminen, L Animal pharmacokinetic studies. In Ophthalmic Drug Delivery Systems; Mitra, A. K., Ed.; Marcel Dekker, Inc.: New York, 1993; pp 121-136.

(29) Schoenwald, R. D. Ocular drug delivery. Pharmacokinetic considerations. Clin. Pharmacokinet. 1990, 18 (4), 255-69.

(30) Al Mahmood, A. M.; Al-Swailem, S. A.; Behrens, A. Clear corneal incision in cataract surgery. Middle East African journal of ophthalmology 2014, 21 (1), 25.

(31) Acheampong, A. A.; Breau, A.; Shackleton, M.; Luo, W.; Lam, S.; Tang-Liu, D. D.-S. Comparison of concentration-time profiles of levobunolol and timolol in anterior and posterior ocular tissues of albino rabbits. J. Ocul. Pharmacol. Ther. 1995, 11 (4), 489-502.

(32) Järvinen, K.; Vartiainen, E.; Urtti, A. Optimizing the systemic and ocular absorption of timolol from eye-drops. STP Pharma Sci. 1992, 2 (1), 105-110.

(33) Araie, M.; Takase, M.; Sakai, Y.; Ishii, Y.; Yokoyama, Y.; Kitagawa, M. Beta-adrenergic blockers: ocular penetration and binding to the uveal pigment. Jpn. J. Ophthalmol. 1982, 26 (3), 248-263.

(34) Lee, V.; Luo, A. M.; Li, S.; Podder, S. K.; Chang, J.; Ohdo, S.; Grass, G. M. Pharmacokinetic basis for nonadditivity of intraocular pressure lowering in timolol combinations. Invest. Ophthalmol. Visual Sci. 1991, 32 (11), 2948-2957.

(35) Huupponen, R.; Kaila, T.; Salminen, L.; Urtti, A. The pharmacokinetics of ocularly applied timolol in rabbits. Acta Ophthalmol. 1987, 65 (1), 63-66.

(36) Tripathi, R. C.; Millard, C. B.; Tripathi, B. J. Protein composition of human aqueous humor: SDS-PAGE analysis of surgical and post-mortem samples. Exp. Eye Res. 1989, 48 (1), 11730.

(37) Urtti, A.; Pipkin, J. D.; Rork, G.; Sendo, T.; Finne, U.; Repta, A. Controlled drug delivery devices for experimental ocular studies with timolol 2. Ocular and systemic absorption in rabbits. Int. J. Pharm. 1990, 61 (3), 241-249.

(38) Salminen, L.; Urtti, A. Disposition of ophthalmic timolol in treated and untreated rabbit eyes. A multiple and single dose study. Exp. Eye Res. 1984, 38 (2), 203-206. 
(39) Ahmed, I.; Francoeur, M. L.; Thombre, A. G.; Patton, T. F. The kinetics of timolol in the rabbit lens: implications for ocular drug delivery. Pharm. Res. 1989, 6 (9), 772-778.

(40) Lee, Y.-H.; Kompella, U. B.; Lee, V. H. Systemic absorption pathways of topically applied beta adrenergic antagonists in the pigmented rabbit. Exp. Eye Res. 1993, 57 (3), 341-349.

(41) Tang-Liu, D.-S.; Liu, S.; Weinkam, R. Ocular and systemic bioavailability of ophthalmic flurbiprofen. J. Pharmacokinet. Biopharm. 1984, 12 (6), 611-626.

(42) Kodjikian, L.; Couprie, J.; Hachicha, W.; Timour, Q.; Devouassoux, M.; Builles, N.; Hartmann, D.; Fessi, H. Experimental intracameral injection of vancomycin microparticles in rabbits. Invest. Ophthalmol. Visual Sci. 2010, 51 (8), 4125-4132.

(43) Shen, Y.-C.; Wang, M.-Y.; Wang, C.-Y.; Tsai, T.-C.; Tsai, H.-Y.; Lee, H.-N.; Wei, L.-C. Pharmacokinetics of intracameral voriconazole injection. Antimicrob. Agents Chemother. 2009, 53 (5), 2156-2157.

(44) Ling, T. L.; Combs, D. L. Ocular bioavailability and tissue distribution of [14C] ketorolac tromethamine in rabbits. J. Pharm. Sci. 1987, 76 (4), 289-294.

(45) Urtti, A.; Salminen, L.; Kujari, H.; Jäntti, V. Effect of ocular pigmentation on pilocarpine pharmacology in the rabbit eye. II. Drug response. Int. J. Pharm. 1984, 19 (1), 53-61. 